\title{
A casa como tempo: a bilheira e as três temporalidades
}

A subjetividade se constitui a partir de vários elementos socioculturais, sendo um deles o modo de morar. Dentre outras dimensões utilizadas para a análise da "moradia", a temporalidade se destaca, seja pela via da rotina, seja pela via da ordenação espacial da experiência que se estabelece entre os habitantes e sua casa.
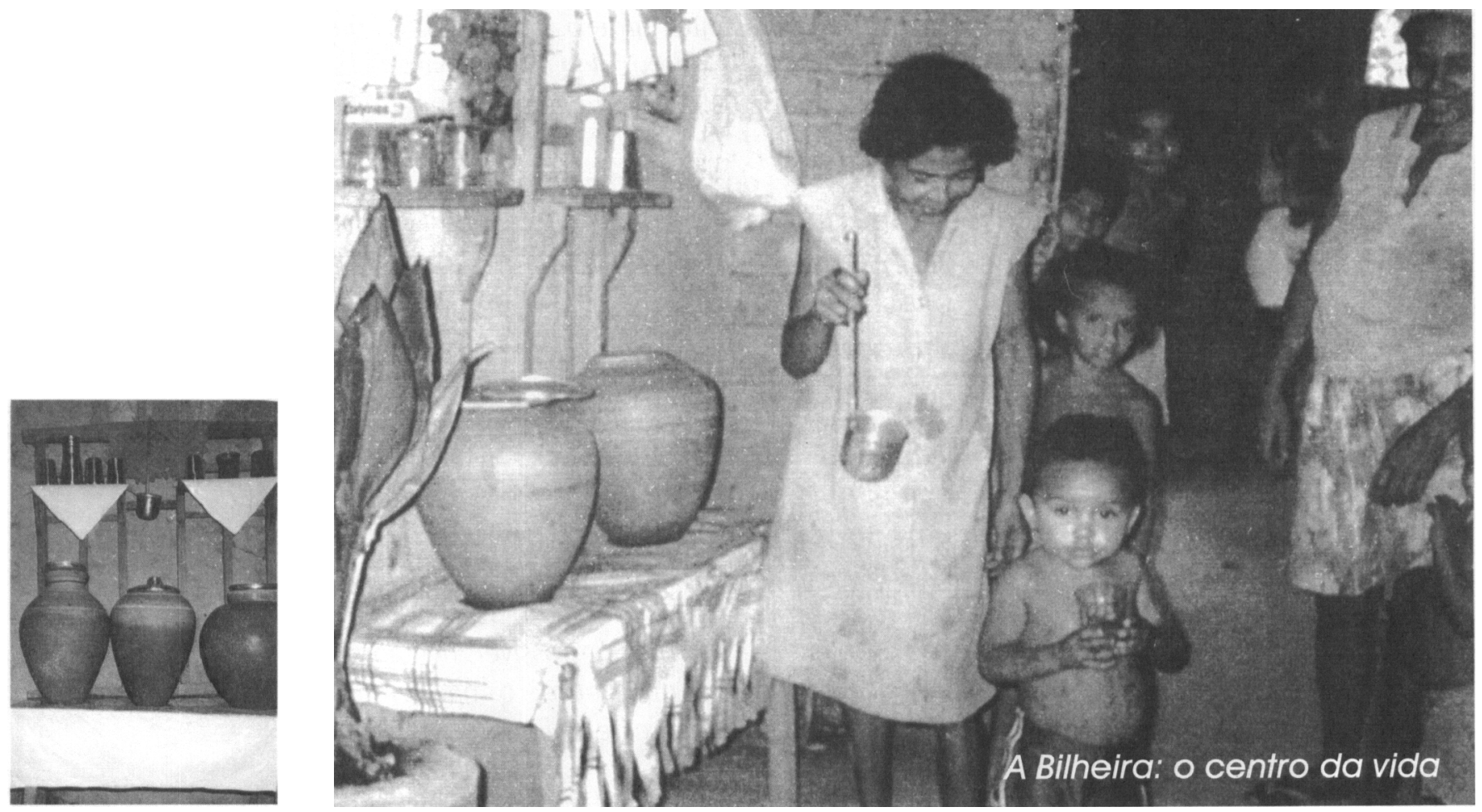

E

ste estudo é parte de um programa de pesquisas cuja meta final é possibilitar a compreensão e análise de dimensões em torno das quais se constitui o modo de morar no Brasil. Trata-se de um programa que pretendeu informar sobre a constituição da subjetividade, em geral, e sobre os componentes socioculturais desta constituição no caso do sujeito brasileiro. Pretendeu, ainda, detectar modelos e processos identificatórios a partir dos quais será possível compreender aspectos do contexto do desenvolvimento infantil.

Rabinovich

Psicóloga clínica pesquisadora do Centro de Estudos do Desenvolvimento Humano, mestre em

Psicologia Experimental e doutora em Psicologio Social pelo Instituto de Psicologla/USP. A fase de campo deste estudo teve apolo da Pastoral da Criança, e sua elaboração posterior, da FAPESP.

O estudo' de que este artigo é parte teve como objetivo imediato analisar alguns dos elementos psíquicos da dinâmica "dentro-fora" a partir do estudo do "meio". Propôs que isto fosse feito através do estudo da seleção, composição e orquestração de "coisas" em uma delimitação espacial que pode ser denominada "moradia", tendo como universo de pesquisa três estudos de caso: o de uma região rural no Piauí, o de moradores urbanos de rua e o de moradores urbanos de baixa renda, ambos em São Paulo.

Foram sugeridas, nesse estudo, quatro dimensões para análise da moradia: simbólica, corporiedade, poética e temporalidade. O presente estudo objetiva apresentar a dimensão de análise temporalidade conforme o estudo das moradias da zona do Cocal, Piauí. 


\section{A Temporalidade}

Vários autores apontaram para uma complexidade inerente ao campo de estudo das moradias que deveria ser resguardada na coleta e na análise dos dados e que implica em levar em consideração a temporalidade, vista, contudo, sob diversas acepções. Para Werner, Altman \& Oxley (1985), o tempo tem sido uma importante parte - embora usualmente apenas implícita - da pesquisa sobre relaçōes interpessoais e uso da casa. Realizou, sob tal perspectiva, um estudo da casa em termos de tempo, considerado como linear e cíclico. Robert Lawrence (1987b), descreve a moradia como uma unidade complexa que define e é definido por fatores culturais, sócio-demográficos, psicológicos, políticos e econômicos. Para este autor, o projeto, significado e o uso do interior de uma casa só podem ser compreendidos a partir de dimensões culturais, sóciodemográficas e psicológicas, entendidas como tendo relações recíprocas em termos de uma perspectiva histórica dual. Esta perspectiva dual refere-se a questōes temporais de longo termo - sócio-históricas, e de curto termo - a história particular dos indivíduos. Dentro desta perspectiva, este autor realizou um estudo arquitetônico, histórico e etnográfico de moradias australianas (1987a), comparando-as com o desenvolvimento de moradias inglesas.

Já para David Saile (1985), as moradias refletem o interjogo dialético entre indivíduo e sociedade, principalmente o interjogo temporal.Kimberly Dovey (1985) estrutura a questão da temporalidade ao interpretar como uma das propriedades da moradia a de ordenar a experiência espacialmente, socioculturalmente e temporalmente. Esta dinâmica dá-se dentro de um quadro dialético ordem/caos: o tempo seria responsável pelo sentido de familiaridade enraizado em rotinas corporais, nas coisas e na experiência de "interioridade". O papel do ambiente físico seria o de uma espécie de âncora mnemônica que estabelece quem somos através de onde viemos: uma identidade temporal não apenas ligada ao passado mas também ao futuro. "O crescimen- to da identidade requer uma certa liberdade de interação entre presente e futuro, entre nossas experiências e sonhos" (p.43). Referente ao tempo, haveria uma orientação temporal do espaço, uma organização temporal da identidade e um processo temporal dialético. "A casa é estática mas a moradia é fundamentalmente dinâmica e orientada por processos dialéticos e transações que mudam no tempo" (p.48).

Em uma abordagem fenomenológica da casa como um conceito heurístico em que ela não é nem sujeito nem objeto, Pascal Amphoux e Lorenza Mondada (1989) concebem o chez-soi como generativo, e não apenas como normativo, positivista, reducionista, "racista ou reacionário", "caracterizando-se por sua dinâmica no próprio movimento do que o constitui, o que aparece como o lugar de um acavalamento de temporalidades diferentes". Propõem um tempo discreto e paradoxal, que coloca as questões da sincronização, da descontinuidade e da imediatização dos ritmos e das atividades domésticas, composto por temporalidades diferentes: tempo estacionário (divino, da eternidade), tempo linear (progressivo ou regressivo, mensurável e causal), tempo cíclico (eterno retorno, regularização dos ritmos, hábitos), tempo discreto (pontual e descontínuo, eterna reconstrução em uma contínua descontinuidade). O chez-soi é visto como "doador do tempo" mas também, do ponto de vista fenomenológico do espaço através do tempo, como confrontação entre um passado reativado e um futuro antecipado.

Desse ponto de vista, haveria uma nova apreensão do tempo com conseqüências sobre o chez-soi. A aceleração constante dos acontecimentos, por exemplo, torna muito difícil a fixação em um modelo de referência, o que pode ser observado em uma renovação acelerada e acumulação de gadgets perecíveis ou na reivindicação de autenticidade de uma mobília ou modo de vida. A lógica do ganho de tempo estaria sendo substituída pela lógica da perda de tempo, com novos objetos técnicos

\section{A bilheira foi considerada um eixo porque fol uma constante em torno da qual se proces- saram transforma- ções}

1.Refere-se à tese de doutorado intitulada Vitrinespelhos transicionais da identidade: um estudo de moradias $e$ do ornamental em espaços sociais liminares brasileiros, defendida no Instituto de Psicologia. Universidade de São Paulo. tendo como orientadora Eda Terezinha de Oliveira Tassara. Bolsista FAPESP (processo n.94/1830-4). 
propostos pelo mercado não visando a economia do tempo (eletrodomésticos, meios de transporte) mas modos de gastar o tempo livre na casa (produtos informáticos, tecnologias de ilusão...). Além disto, estar-se-ia passando de uma concepção de continuidade, em que a experiência espacial era dominante, a uma concepção de descontinuidade, na qual a experiência temporal torna-se dominante: deve-se saber viver o dia a dia, reagir o mais rápido; há incerteza dos itinerários profissionais, dos itinerários residenciais; não se constrói para a vida mas por alguns anos; o espaço arquitetural abre-se, torna-se transparente $\mathrm{e}$ efêmero, com um planejamento para o uso livre dos espaços internos, superfícies de vidro $\mathrm{e}$ a obsolescência da construção.

Para esses autores, a televisão pode ser considerada como "uma nova janela, abrindo a casa não mais para o seu ambiente imediato mas para um espaço infinito - tela translúcida que veste a materialidade das separações de uma transparência ilusória em imagens fugidias onde se pode interromper o fluxo pela simples comutação. A representação da sala concentrava um público em um espaço, a representação televisual a concentra no tempo; a biblioteca permitia reunir os leitores de informações diferentes em um mesmo lugar, a tela permite difundir a mesma informação a pessoas dispersas" (op. cit., p.143).

No estudo seminal do vilarejo de Minot, na França, por Françoise Zonabend (1980), o tempo se impôs como central à análise, resultando nos conceitos de tempo do vivido, estudado na casa; tempo da vida, analisado pelas relações entre sociabilidade e seus lugares; tempo da coletividade, de duração estável, cíclica, marcado pelo perpétuo recomeço, pelo eterno retorno para "o mesmo", mergulhado na origem do grupo, e no tempo familiar, memorizado pelos nomes próprios que classificam em uma linhagem e inscrevem em um vivido social. O tempo vivido e da vida são divididos entre um "ontem" e um "hoje", e são ciclicamente negados pelo retorno ao "mesmo" do tempo da coletividade.
Nos nossos estudos, questōes envolvendo o tempo impuseram-se desde a primeira pesquisa de campo (Rabinovich, 1992b), onde observamos que a desorganização materna aparecia associada à falta de rotinas e a uma relação simbiotizada com o bebê. Deste modo, o primeiro indício de que o tempo se achava no espaço veio, para nós, através das rotinas, compreendidas, atualmente, como açōes apoiadas no espaço que estruturam o tempo. $\mathrm{Na}$ segunda série de nossas pesquisas de campo realizadas com os sem casa (Rabinovich, 1992a), o tempo veio a poder ser "visto" através da instabilidade das moradias que estavam em perpétua transformação. Inspirada em Hall (1983) e em seus estudos sobre a cronêmica - o modo como o tempo se acha presentificado no espaço - introduzimos em nossas considerações dois novos conceitos: o de tempo monocrônico e o de tempo policrônico. Enquanto o segundo estaria relacionado a sociedades coletivizadas, o primeiro referir-seia à compartimentalização dos espaços a partir de um conceito de vida privada e íntima. Deste modo, o conceito de tempo passou a integrar o de modo de vida, e, conseqüentemente, o de modo de morar.

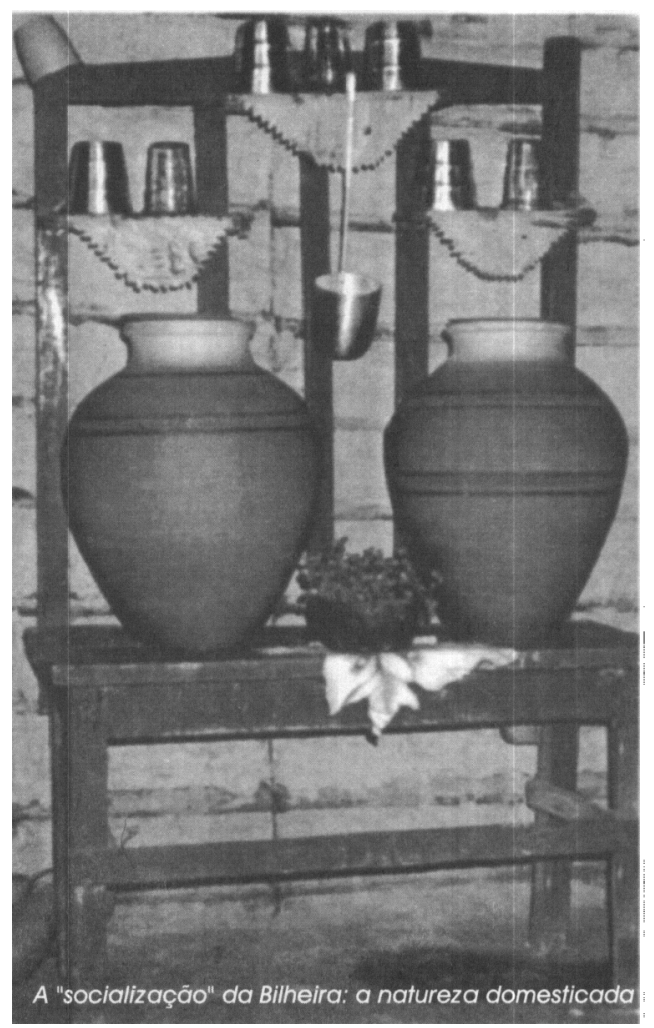


Outro conceito desenvolvido a partir do estudo dos sem casa foi o de "tempo vivido" como o tempo fenomênico do presente, passado e futuro, construído, contudo, socialmente, dado indicações de que o corte do passado era um impedimento para o futuro, ficando o sem casa preso ao presente como o único tempo possível. O terceiro elemento temporal surgido no estudo dos sem casa foi a transformação contínua das moradias, como se a transformação compensasse a ausência de "propriedade" através de uma "apropriação" permanente. Em função disto, fomos estudar os túmulos na condição de moradias "imóveis", tentando entender como a visão de tempo "eterno", não funcional, achar-se-ia representada no espaço.

Finalmente, o estudo desenvolvido no interior do Piauí (Rabinovich, 1994) possibilitou uma leitura diacrônica em um recorte sincrônico, donde emergiram categorias que correspondem, por analogia, às de Braudel (1983). Através de uma abordagem que desenvolveu uma "arqueologia do moderno" por meio das "coisas" e de sua localização no espaço, "rastreou-se" as pistas sobre tempos diversos e simultâneos. Deste modo, de um recorte pouco abrangente, pode-se alcançar tempos longínquos porque nele ficaram inscritos registros a serem decifrados, e que remeteram às três temporalidades de Braudel. Este autor decompõe a História em planos superpostos, distinguindo um tempo geográfico, um tempo social e um tempo individual. O tempo geográfico seria quase imóvel: seria o tempo das relaçōes do homem com o meio que o rodeia; o tempo social referir-se-ia à história dos grupos e dos agrupamentos, e o terceiro, à dimensão do indivíduo, de seus sonhos, cóleras, ilusões.

No presente estudo, apresentaremos o estudo da organização do espaço de 20 casas da zona do Cocal, interior do Piauí, conforme efetuadas a partir da bilheira e do seu entorno, utilizando as três temporalidades de Braudel.

\section{Método}

Este estudo inscreveu-se dentro de um programa de pesquisas mais amplo - a de buscar dimensões que informassem o contexto de desenvolvimento infantil conforme visto no modo de morar - e como resposta ao etnocentrismo comprometido com um conhecimento da realidade que faria derivar de uma única realidade social as condições do desenvolvimento e suas conseqüências sobre ele.

Esta problemática ocasionou um segundo programa de pesquisas visando conhecer a realidade social e relativizar a posição do observador no campo variando o campo. O presente estudo está inscrito dentro deste segundo programa de pesquisas e objetivou conhecer algumas das relações entre a construção da identidade e a construção ecosócio-histórica da moradia. Embora um recorte do primeiro programa de pesquisas, ele tem uma abrangência major do que o dele, dado o contexto "conter/envolver" o desenvolvimento.

Para isto, foram realizados três estudos de campo que constituíram o corpus empírico do estudo: um estudo em uma zona urbana; um estudo de moradores de rua; um estudo em uma zona rural. Um outro estudo, visando complementar os demais, mas sem ter as características destes, foi realizado: o estudo de alguns túmulos em alguns cemitérios.

O corpus empírico, portanto, compôs-se de quatro estudos de caso: Vila Madalena, sem casa, Piauí rural, casa dos mortos.

Dentro da pré-condição de fazer aparecer o não-hegemônico, seguiu-se o raciocínio de que cotejando extremidades teríamos informaçōes sobre o "meio". Cada estudo gerou a necessidade do seguinte, que o complementava, de um lado, e opunha-se a ele, de outro. A escolha de populações e/ou situações liminares complementou a expansão dos limites da observação ao considerar a liminaridade uma condição emergencial no sentido de "des-cobrir" o que estaria encoberto em zonas mais centrais do universo. Em conseqüência, surgiu um outro estudo, decorrente e incluído nos demais: o "caso brasileiro".

Os estudos de caso - Vila Madalena, sem casa, Piauí - partiram da descrição detalhada do observado. As "coisas" foram vistas sistematica-

\section{Darcy Ribeiro \\ (1995, p.109) define a identidade brasileira como um vazio, um não centro, "uma terra de ninguém" decorrente da "formação identitá- ria" dos mamelu- cos, filhos de mãe índia e pai euro- peu, que trabalha- vam para o europeu mas se comportovam como índios, rejeitados por ambos. A mestiça- gem seria, para nós, esta herança materna, transmiti- da intergeracional- mente no modo de cuidar da casa e da criança, e a "Iíngua materna"}


2. Vemacular ou indigenous, significando etimologicamente, Ter nascido dentro (Dovey, 1985, p.42). Segundo Mercer (apud Lawrence, 1987', p. 16) "construçöes vernaculares são aquelas que pertencem a um tipo que é comum numa dada área em uma dada época".

3. Pascal Amphoux (1989 p.182) refere-se ao itinerário do telefone para mostrar a mudança da identidade social da pessoa e da representação simbólica dos objetos, móveis ou serviços técnicos. Segundo ele, o telefone passou sucessivamente do vestibulo para a sala, depois para o quarto, antes de se multiplicar em várias peças: "mais ele se aproxima da cama. mais a duração da conversa é longa. Portanto, passa-se do equipamento ao consumo". 0 mesmo ocorreu com a televisāo $e$, atualmente, com o computador, o que ilustra o conceito de prática sóciosimbólica. Segundo Jeanclaude Kauffinan (1994, pp.5358), pode-se observar uma tendencia a uma mudança entre - lugar da cozinha $e$ do computador: a cozinha. delegada a um cômodo pequeno e pouco ensolarado, é hoje um centro de atividade socializada onde os moradores se encontram, havendo a tendência a ter balcóes separando-as da sala. integrando cozinha $e$ sala. Já computador surge como uma atividade importante, solitária, necessitando de espaço sem sol, protegido. mente dentro de outros sistemas que as continham: social, geográfico, familiar. Cada um dos estudos de campo teve características etnográficas realizadas por observação naturalística que objetivaram alcançar, através da derivação empírica de categorias de análise, uma interpretação dos resultados.

Procurou-se modos de análise em um sentido interpretativo. Categorias empíricas nāo deram conta deste propósito; categorias apriorísticas não poderiam ser utilizadas pois o campo devia ser organizado a partir dele próprio. A descrição das partes não nos possibilitou chegar à interpretação porque, neste caso, a visão do todo teve que se dar concomitantemente $\mathrm{e}$ sucessivamente à análise das partes. A derivação das variáveis para a obtenção das categorias deu-se, pois, por sucessivas elaborações, abstrações, sínteses, e novas análises, em sistemas hierarquizados onde lacunas requereram novas análises, sínteses e abstrações.

\section{O estudo do Piauí: as temporalidades de Braudel}

O estudo no Piauí revelou a brasilidade. Brasilidade está significando que falar do Piauí é falar do Brasil, de todos os brasileiros, com todas as suas diferenças regionais, falar de algo comum a todos do/no Brasil.

Isso remete à questão da mestiçagem e da temporalidade: resulta que, através do estudo dos arranjos espaciais das coisas em uma delimitação espacial denominada casa, foi possível traçar uma arqueologia da memória da construção da idẹntidade da brasilidade. Esta arqueologia só pode ser empreendida no Piauí pela relativa uniformização das moradias, de modo que, no modelo de uma ciência experimental, algumas variáveis manifestaram-se apresentandó valores variáveis e outras, constantes. Deste "quase-experimento", podese traçar o seguinte relato.

\section{A bilheira e ontorno}

A análise a ser apresentada partiu do conjunto empírico de dados e não de um modelo previamente estabelecido. As "coisas" presentes nas casas no Piauí foram agrupadas em dois eixos ao longo dos quais colocar-se-á o sistema descritivo analítico: a bilheira e o entorno.

\section{A bilheira}

A bilheira é uma peça do mobiliário presente, de certa forma, em todas as casas. É um móvel de madeira, semelhante a uma estante. Sobre a prateleira inferior estão dispostas uma ou duas bilhas: grandes talhas ou vasos de barro para conter água. Em algumas casas, a bilha é um filtro de barro para água. Sobre esta prateleira com as bilhas, na parte superior, estāo duas ou três prateleiras, mais estreitas e menores, sobre as quais estão recipientes para beber água: canecas de alumínio ou copos de plástico colorido, tendo geralmente entre eles, em posição central, uma concha de alumínio destinada a pegar água de dentro da bilha e colocá-la no copo.

A bilheira foi considerada um eixo porque foi uma constante em torno da qual se processaram transformações. $\mathrm{O}$ eixo bilheira transformou-se em três direçōes que foram denominadas "tempos": tempo geográfico, tempo social e tempo psicológico.

A população estudada estava excluída do consumo de massa, não apenas por causa da distância entre a zona estudada e grandes centros de consumo, mas porque viviam do extrativismo e do plantio, não possuindo renda. Suas moradias e modo de vida forneceram um exemplo de inclusão no sentido de originalidade, que estamos denominando vernacular ${ }^{2}$. Devido a isto, pudemos apreender o tempo geográfico, um tempo longo, resultante desta dimensão indigenous, original, no seu confronto/mescla em direção ao novo.

O tempo geográfico, no presente estudo, compreendeu a lenta transformação no modo de obter/conter a água. Refere-se ao modo como a água chega na casa: pelo rio ou fonte; por poço cacimbão, cacimba ou tubular; pela 
água encanada. Ele pode ser estudado também pelo tipo de material utilizado nos adornos da bilheira: "natural", apropriado/reciclado e funcional/próprio. O material natural seria o próprio à região, feito de materiais encontrados no local e segundo o sistema de produção regional. O reciclado é o material apropriado de outro contexto e resignificado na bilheira, como plásticos, jornal, embalagens, propaganda eleitoral, etc. $\mathrm{O}$ funcional é o material adquirido ou realizado de modo próprio à função. Ex.: toalhinha de crochê manufaturada ou industrializada.

O tempo social foi apreendido através da variação na relação entre a bilheira e o cômodo onde se encontrava. Esta transformação deu-se em dois sentidos: no sentido cômodo/casa e no sentido cômodo/cômodo. No sentido cômodo/casa foi do único móvel da casa até se tornar dispensável devido a uma futura rede de água encanada. Ao mesmo tempo que esta passagem acontecia, a bilheira ia mudando de cômodo, de um cômodo intermediário para a sala principal, para uma sala secundária, para a cozinha, para desaparecer. Portanto, o tempo social se apreende pela existência ou não da bilheira em relação ao cômodo por ela ocupado.

A segunda transformação dentro do tempo social foi a passagem não-centro - centro descentração. De uma ausência de centro devido à ausência de coisas, a bilheira passa a centro da casa. Em seguida, passa a disputar este centro: primeiro com mesa e cadeiras colocadas no centro da sala; depois, com "poltronas" colocadas em círculo no centro da sala. Este sentido é a posição que a bilheira ocupa no cômodo em relação às demais coisas do cômodo ${ }^{4}$. O tempo social refere-se, de um modo geral, à posição que a bilheira ocupa na casa: seria a relação espaço-exterior.

A terceira transformação é o tempo psicológico. Concomitantemente às mudanças com relação aos cômodos, ela se transforma de algo simples até adquirir uma organização complexa até desaparecer. De uma peça contendo bilhas e copos, é acrescida de toalhinhas, etc., até ser cercada de objetos formando uma composição, tornando-se o centro visual da casa até o seu desaparecimento ${ }^{5}$.

O tempo psicológico refere-se às transformações internas à bilheira: seria a relação espaçointerior.

Uma variante do tempo psicológico seriam os cuidados, definidos como o conjunto de ações realizadas a partir de conceitos de organização espacial, correspondendo usualmente à arrumação.

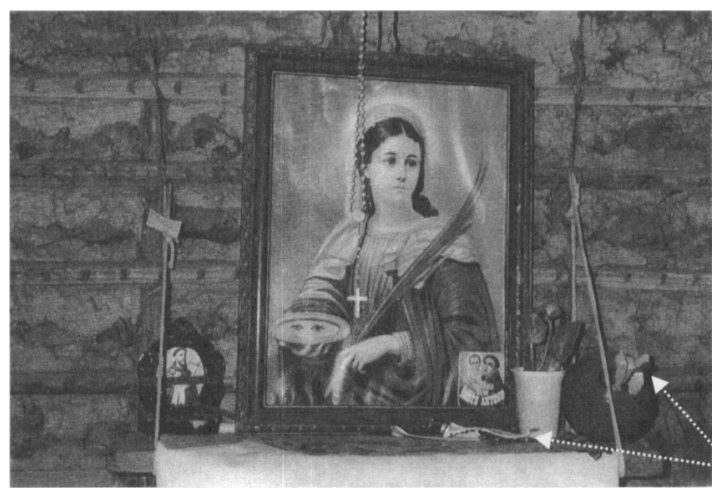

- Altar do Sagrado + O altar da Modernidade: escovas/ Creme Dental

A bilheira foi considerada o eixo condutor da análise das moradias e dos adornos porque nela pareceu se inscrever a(s) história(s) do ornamental através da espacialização da "coisa". O fato dela emergir como eixo condutor deve-se, provavelmente, à sua força como elemento mítico e ritualístico associado à água em uma cultura caracterizada por secas endêmicas.

\section{O "entorno"}

O entorno é o outro eixo, complementar ao eixo condutor da análise bilheira. Devido às condições homogêneas nas casas referentes às técnicas de construção, tipos de materiais utilizados, dimensōes e objetos presentes, foi possivel construir uma espécie de "linha de base" que resultou, assim como com a bilheira, em um modelo básico a partir do qual realizar a análise do ambiente. Muitas variáveis importantes, como portas, janelas, tetos, paredes, chão, localização, tipo de moradia, etc., puderam ser eliminadas enquanto análise interna ao estudo, no caso do Piauí, devido à sua constância.
4. Na zona do Cocal, a cozinhaé um lugar pouco valorizado na casa, em algumas, apenas o fogão de barro. A ausência de móveis toma tudo muito fluido, muito móvel. Quando os móveis chegam, a pequena mesa para duas pessoas é substituída por uma mesa grande, com cadeiras $e$ não mais banquinhos. Com 0 aumento da casa, esta mesa passa para a sala secundária sendo a principal ocupada pela poltronas dispostas em círculo, havendo, concomitantemente, 0 aparecimento da estante.

5. O tempo psicológico estaria relacionado com o investimento libidinal no objeto, sendo um indicador da importância daquele objeto como "organizador psíquico". A maior parte dos estudos sobre identidade $e$ ornamentação referem-se a esta relação (ver Csikszentmihalyi e Rochberg Halton 
Algumas variáveis ligadas à construção tiveram suas diferenças captadas por duas variações observadas em relação à bilheira: os cuidados $\mathrm{e}$ a mudança do tipo de cômodo. Os cuidados à

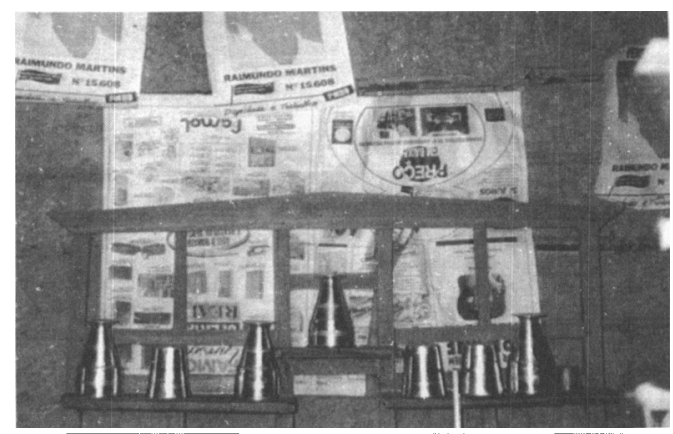

6. Estas divisórias têm a função de impedir a visão e de decorar pois são de cores vivas. Enquanto nas moradius populares do bairro paulistano de vila Madalena, e mesmo nos sem casa, parecia haver uma "luta" para dividir os espaços, para diferenciá-los, aqui não: os espaços estavam garantidos dentro da ordem sócio-familiar. as divisórias, assim como a porta de entrada, demarcavam o dentro/fora, sem necessitar de intermediações. Quando havia corredores, eram passagens internas, näo lugares que separavam e dividiam. A porta de entrada estava sempre aberta, e ao entrar, estávamos totalmente dentro; assim como ao sair, estóvamos totalmente fora. Isto ocorria, objetivamente, devido à ausência de janelas $e$ da intensa claridade exterior porém, subjetivamente, a entrada na casa significava uma aceitação tal que nos sentiamos "de casa". Esta mesma sensação ocorria com os sem casa: uma vez dentro de seu espaço, saiamos da "rua" $e$ entrávamos em um outro universo, de onde víamos a nós próprios de outro ponto de vista, inclusive distante de quem somos normalmente. Esta força de pertencimento parece-nos ser algo essencial nestes modos de vida liminares, onde näo há transiçöes que corresponderiam a "amortecedores", no sentido emocional de impedir a vivência de choques violentos. $A$ ausência de intermediaçöes corresponderia também a instâncias epistemológicas, pois significam "as palavras $e$ sua sintaxe", ou seja, a estrutura mental, $e$ valores bilheira apareceram associados a cuidados gerais da casa (arrumação), enquanto o cômodo onde a bilheira estava localizada associava-se ao número de cômodos, de coisas, de móveis, ou seja, ao tempo social.

O entorno pode ser analisado através dos seguintes descritores: divisórias, altares, disposiçāo dos objetos nas paredes.

As divisórias são as separações entre os cômodos, classificadas como ausentes/ presentes e tipo (cortinado florido e rendado) ${ }^{6}$.

Os altares são disposições de coisas em torno de algo central, geralmente com a sugestão de verticalidade. Encontramos três tipos de altares: sagrado, profano e da modernidade. $\mathrm{O}$ altar sagrado consistiu de quadros de santos, acrescidos ou não de outros elementos. Os santos eram retratados de forma vivamente colorida. O altar moderno consistiu de dois elementos: a escoveira e a mesa com televisão ou rádio. A escoveira era um suporte com escovas de dente, localizado no alto da parede da sala. Dada a inexistência de outros elementos, o colorido das escovas de dentes, sua quantidade e localização privilegiada, a escoveira ressaltava dentro do conjunto. $\mathrm{O}$ altar de rádio/TV consistia em uma mesa com o aparelho em cima. Recebia tratamento equivalente ao santo ou bilheira, ou seja, toalhinhas e outros objetos eram colocados próximos formando uma unidade visual.

Estes altares receberam acréscimos de elementos resultando em graus variados de complexificação. A complexificação se deu por número, tipo e diversidade dos elementos acrescidos.

A seqüência possível dos acontecimentos pareceu-nos ser a seguinte: primeiro a bilheira, depois foram acrescidos os outros dois focos principais, sagrado e profano. Isto representou uma tendência à centralização através de focos. Estes focos estão sendo pensados como as raízes identificatórias, no sentido de autóctone, que jorra da própria terra. Os focos seriam, pois, o sentido da identidade incorporado na casa'.

Após esta tendência a centralizar, ocorre uma tendência descentralizadora: os focos são atomizados, aparecendo como pequenos e discretos quadros de santos ou mesmo ausência deles, enquanto o altar moderno foi se instalando em estantes compostas com vários objetos "comprados", um sinal de status: bonecas, bichinhos de vidro, figuras em cerâmica, etc.

Esta descrição poderia corresponder à transformação do tempo mítico em tempo funcional, do relógio. A atomização é acompanhada do aparecimento de relógios de parede e de folhinhas, confirmando, supostamente, esta interpretação ${ }^{8}$.

Este "caminhar" decorativo das "coisas" é um trabalho interpretativo, baseado em evidências empíricas, possível porque foram apreendidos dois níveis concomitantemente, um sincrônico e um diacrônico. Isto foi possível por causa das características semelhantes que variavam em conjunto com outras modificações.

Estamos propondo, pois, para o entorno, dois conjuntos de análise. Um envolve os focos: presença/ausência e tipos de focos em sua complexificação; o segundo visa a análise da disposição espacial das "coisas" nas paredes: verticalidade, horizontalidade, circularidade, vazios. 


\section{As três temporalidades}

A bilheira surgiu como eixo condutor da análise das moradias porque nela pareceu se inscrever a(s) história(s) do ornamental através da espacialização da "coisa" devido, provavelmente, à sua força como elemento mítico e ritualístico associado à água em uma cultura ligada a secas endêmicas.

Pode ser considerada um atrator, na terminologia de Gruzinski (1995), uma "coisa" que catalisa em torno de si representaçōes simbólicas sociais ao mobilizar a fusão de energias advindas de várias fontes. Funciona como um organizador de várias influências e dinâmicas, significando um espaço de ordem que se cristaliza, onde universos estão acavalados, mesclados. Condensou, cristalizou e ordenou diversos sistemas de significações que estamos supondo estar na origem da formação identitária mestiça brasileira".

O conceito de mestiçagem, segundo nossa compreensão, corresponde ao de fronteiras de identidade que se dão em tempos culturalmente diversos e em fronteiras móveis. A mestiçagem corresponderia à ausência de centro que decorre de um processo civilizatório onde a maioria sempre foi a "minoria". Parafraseando Michel Serres (1993) é a ausência de um sol único, mesmo que se faça crer que assim seja. E' a resistência cultural que se manifesta no cotidiano, através do uso de palavras e coisas de um modo, mas querendo dizer "outro(s)". De maneira semelhante, Darcy Ribeiro (1995, p.109) define a identidade brasileira como um vazio, um não centro, "uma terra de ninguém" decorrente da "formação identitária" dos mamelucos, filhos de mãe índia e pai europeu, que trabalhavam para o europeu mas se comportavam como índios, rejeitados por ambos. A mestiçagem seria, para nós, esta herança materna, transmitida intergeracionalmente no modo de cuidar da casa e da criança, e a "língua materna".

Os três tempos, acima descritos na análise da bilheira, corresponderiam, por analogia, às três temporalidades de Braudel: longa, social e psicológica. Esta analogia permitiu expandir a compreensão dos fenômenos psíquicos.
Uma dessas expansões foi entender o sujeito a partir de sua capacidade de historização, e não apenas como realidade psicossocial. Colocar o sujeito na História é percebê-lo no tempo geográfico, da evolução humana; é percebê-lo no tempo social, da subjetividade do homem mítico para a do homem mitopoético; é percebê-lo como sujeito psicológico, epistêmi$\mathrm{co}$, social e afetivo, em sua singularidade. Esta tríplice leitura teria de ser feita para se poder chegar ao conhecimento histórico, que é, no fundo, o problema do conhecimento: a(s) história(s) condiciona(m) como o indivíduo vai elaborar a sua sucessão de fatos, como vai arquivá-los, como vai formar estes arquivos.

O fato histórico, visto destas várias acepções, faz originar tanto o sujeito histórico quanto o inconsciente das temporalidades, que seriam os modos de configuração do inconsciente: arquetípico, social, individual. Segundo Eda Tassara (com. Pes. 1995), o sujeito histórico poderia ser visto como um conjunto de relações repetíveis, através das quais se dá o "eu" e a identidade, que afloram no processo histórico feito pelo sujeito segundo o seu histórico, a história vista como produto e produtora da subjetividade. $O$ momento, estruturado e estruturante, do ser-humano - a mediância, segundo Augustin Berque (1995), seria a relação do indivíduo com o meio (espaço) que configura a meta-história, ou seja, o fazer-se homem ao fazer-se histórico, temporal. $\mathrm{O}$ desejo constituir-se-ia neste momento, sendo mediado por estas temporalidades. A terceira expansão refere-se à conservação da memória nas coisas: as memórias podem ser mantidas e, concomitantemente, desconhecidas, o que corresponderia à arqueologia do cotidiano na visão de Boaventura de Souza Santos (1995). Esta conservação, percebida devido ao método da descentração do estudo, é possível devido aos mecanismos de resistência implicados em práticas sócio-simbólicas do morar.

O endeusamento no altar propiciou a visão da origem mítica e societária brasileira, assimilando tanto o passado arquetípico quanto o futuro utópico, deixando, contudo, no centro, um vazio identitário mestiço. fundantes como, nos povos primittivos e outros, onde 0 pórtico é a passagem do sagrado ao profano.

7. Os focos podem ser pensados como "pontos fixos de valência positiva", correspondendo a uma das funçōes da "maternagem" (parafraseando Damergian, $S$. $O$ papel do inconsciente na interaçāo humana, p.320). Para a criança, os pontos fixos são o que permitem a permanência do "objeto permanente" $e$ do processo identificatório. No ambiente, os focos indicariam a existência de pontos fuxos e as redes de significaçóes propostas por eles como interaçōes identificatórias.

8. Pode-se pensar que o aparecimento da estante $c$ de objetos industrializados indicam o desejo tanto das coleçöes - "o gosto burguês de agrupar, de organizar $e$ de justapor objetos. sua acumulaçāo vista como um meio de acentuar o contraste entre o espaço doméstico e o do trabalho" (Després, 1989, p.5). quanto de ter o meio urbano industrializado. Havia, por exemplo, coleçöes de latas de leite vazias. De um modo geral, há uma tendência a decorar com objetos funcionais decorados, observado também nos sem casa.

9. Estamos nos apoiando nas idéias de Serge Gruzinski (1995), para quem a compreensão do processo de colonização americano tem que ser feita a partir de uma des mistificaçāo da mitologia européia maniqueista. Para ele, houve e há "fronteiras fractais", móveis, mundos que transitam de um para outro através da circulaçāo de objetos $e$ palavras, criando uma zona "estranha" (étrange). emblemática de mundos intermediários. $A$ esta zona estamos chamando de mestiçagem: zonas não claras, incertas, em gestão, imprevistas e incontrolaveis. Segundo Serge Gruzynski, o sincretismo pode ser pensado de um modo muito mais generalizado do que aplicado d̀ 


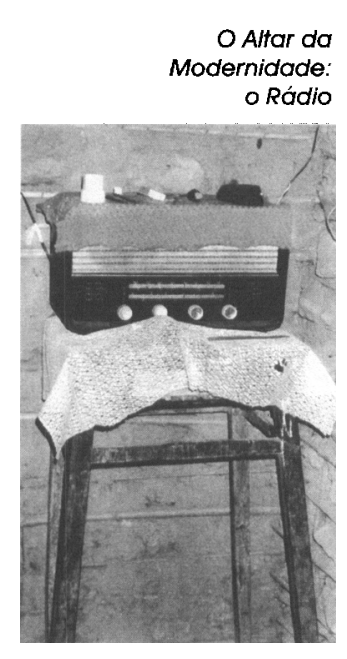

religiāo, existindo também nas palavras e nas coisas. É por isto que o estudo do cotidiano pode revelar uma história que se acreditava esquecida ou mesmo suplantada: porque ela continua viva nas coisas. o estudo dos objetos como atratores implicaria em uma não separaçāo do contexto $\mathrm{cm}$ suas partes, segundo as ciências e suas "logicas", e em estudar o fenômeno a partir de suas manifestaçojes, qual seja, como as coisas se colocam $\mathrm{em}$ seus lugares, como aparecem os espaços de ordem.

10. Este autor considera o epistemicidio um dos grandes crimes da humanidade pois "sobretudo depois que a modernidade se reduziu a modernidade capitalista, se procedeu à liquidação sistemática das alternativas quando (...) não se compatibilizam com as práticas hegemonicas" (p. 324-5). Propōe a deslocação radical dentro de um mesmo lugar, do centro para a margem, para se ter uma visäo telescópica do centro e para se ter uma visäo macroscópica do que ele exclui para poder ser centro, em uma busca das utopias silenciadas. o conceito de arqueologia virtual do presente, segundo Tassara (1996) faria parte do paradigma do emergente, significando escavar sobre o que nào foi feito e porque nào foi feito, ou seja, procurar nas entrelinhas o texto.

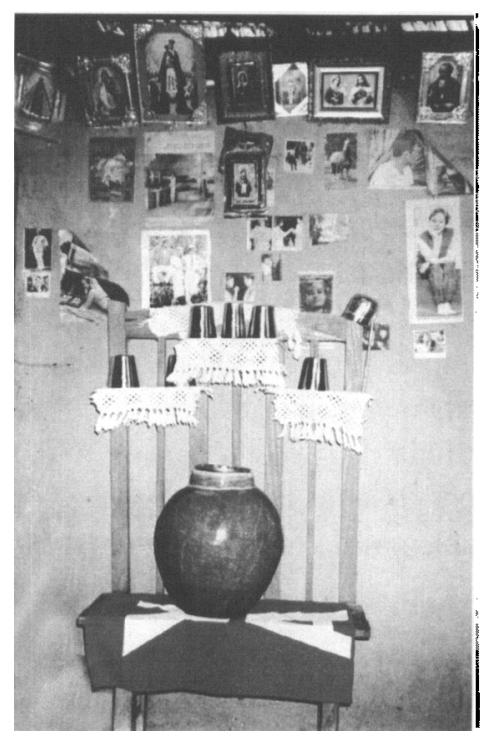

A complexificaçõo da Bilheira

Essa é a questão histórica mais ampla da constituição da identidade dos brasileiros: um aspecto longo, que, nos termos do Movimento Antropofágico, "nos une a uma natureza poderosa, terrorífica, tropical, que induz um temor primitivo. Este corresponde, de um lado, a um instinto antropofágico, e de outro, a uma imagem de Deus: graças ao ritual canibalístico, era incorporado, num ato de extrema vingança, a alteridade inacessível dos deuses, fincando-os na terra, e com eles estabelecendo a convivência familiar" (Nunes em Andrade, 1990, p.22).

Enquanto uma cultura condicionaria a permanência pela posse de objetos, outras, canibalísticas, condicionariam esta permanência pelo rastro nos corpos. No Brasil, haveria uma contínua incorporação de símbolos, com os quais não há identificação, ficando no centro um vazio: o herói sem nenhum caráter, Macunaíma.

Esta longa temporalidade - intuída nos sem casa devido ao nomadismo e à cultura através do uso de símbolos e não de posses -, foi concretizada na transformação da água, como um elemento vital, endeusada no Piauí. Este endeusamento, através do altar, é o sagrado no cotidiano, o altar profano, o tempo do sagrado instituindo o que DaMatta (1985) chamou "os mortos" como uma dimensão da realidade brasileira. $\mathrm{O}$ modo de destruir a onipotência dos deuses é trazê-los para a terra, fincando uma passagem para eles, uma linha aberta de comunicação permanente, que torna surreal a realidade pois sempre se refere a algo que não está lá.

Para Oswald de Andrade, o que os homens não conseguiam dominar, e temiam, que era o terror primitivo, manifestava-se como entidade estranha e hostil ao homem, primeiro na consciência do sagrado e depois, na atitude devorativa.

O altar do profano, a bilheira, seria a atitude devorativa: a água aprisionada é fincada na terra, estabelecendo-se, através dela, o banquete ritualístico, desreprimindo-se da censura paterna e encaminhando-se para a comunhão: o beber juntos.

O altar da modernidade, por sua vez, seria o que Oswald chamou de "bárbaro tecnizado", o selvagem antropofágico ávido de progresso, que assimila a técnica.

O altar do sagrado seria a dimensão da convivência familiar do sagrado, em uma sociedade relacional onde morre a pessoa mas não a relação, de modo que os antepassados estão presentes no cotidiano. Os santos são como antepassados, com os quais se convive, tornando surreal a realidade.

A incorporação de novos significados sem incorrer em "erro" trouxe para o estudo o conceito de liminaridade, emprestado da antropologia (Turner, 1974), assumida para o povo brasileiro. A liminaridade seria esta condição da subjetividade em que o estado habitual é sua modificação, sua fluidez, incorporando o "outro" sem entrar em contradição, de modo a preservar o passado. Neste sentido, a liminaridade tem uma analogia com o Movimento Antropofágico onde a resistência é uma "trituração", uma abertura sem resistência a conteúdos novos que são re-significados e extrovertidos. Esta resignificação seria uma forma de resistência pela incorporação do resistir à própria identidade que, deste modo, não é destruída pela transformação. 


\section{Conclusão}

Este estudo sugere a inscrição do sujeito psicossocial em tempos concomitantes produzidos em três níveis ou diapasões: um tempo muito longo, o da nossa história planetária, arquetípica; um tempo mensurável em anos, décadas, séculos, social; e um tempo muito rápido, instável, singular, individual, psicológico. Estes tempos se inscreveriam na matéria, desde onde podem ser "lidos".

A bilheira, como atrator, ao condensar várias fontes de energia ao seu redor, ofereceria uma arqueologia da memória da construção da identidade no Brasil, sugerindo a brasilidade como categoria identitária vista como um resultado de mestiçagem/hibridismo cultural.

Amphoux, P. (1989). Configurations domestiques et reconquête de soi: pour une prospective connotative de l'habitat. Em Haumont, N. e Segaud, M. Familles, modes de vie et habitat. Paris: Harmattan.

Amphoux, P. e Mondada, L. (1989). Le chez-soi dans tous les sens. Architecture \& Comportement/ Architecture \& Behavior, 5, no2, 143.

Andrade, O. (1990). Obras completas de Oswald de Andrade: a utopia antropofágica. São Paulo: Globo.

Berque, A. (1995). Paysage et éthique de lenvironnement. Paris: École des Hautes Études en Sciences Sociales.

Braudel, F. (1983). O Mediterrâneo e o mundo mediterrâneo. São Paulo: Martins Fontes, v. 1

Bernard, Y., Lebeau, M.O., Giuliani, M.V.; Bonnes, M. (1987). Pratiques de l'habitat et mondes sociaux. Psychologie Française, 32, no1/2, 65-76.

Csikszentmihalyi, M; Rochberg-Halton, E. (1981). The meaning of things: domestic symbols and the self. Cambridge: Cambridge University Press.

DaMatta, R. (1985). A casa e a rua. São Paulo: Brasiliense.

Damergian, S. (1988). O papel do inconsciente na interação humana. São Paulo. Tese (Doutorado) Instituto de Psicologia, Universidade de São Paulo.

Després, C. (1989). De la maison bourgeoise à la maison moderne: univers domestique, esthétique et sensibilité féminine. Recherches feministes, 2, №1, 3-18. (N. spécial: Lieux et milieu devie).

Dovey, K. (1985). Home and homelessness. Em Altman, L. e Werner, C.M. Home environments. New York: Plenum Press. v.8. Human behavior and environment.

Gruzinski, S. (1995). "Les Ameriques baroques: manifestations et répercussions de l'occidentalisation", École des Hautes Études en Sciences Sociales, Paris. Séminaire.

Kauffman, J.C. (1994). Les espaces du linge. Recherches Architecturales, $\mathrm{n}^{\mathrm{9}} 42$.

Hall, E.T. (1983). The dance of life: the other dimension of time. New York: Anchor Books.

Lawrence, R.J. (1985). A more humane history of homes: research method and application. Em Altman, I. e Werner, C.M. Home environments. New York: Plenum Press.
Lawrence, R.J. (1987). Housing, dwellings and homes: design theory, research and practice. New York, John Willey \& Sons.

Lawrence, R.J. (1987). What makes a house a home? Environment and Behavior, 19, ํo2, 154-64.

Rabinovich, E.P. (1992). Modo de vida e relaçāo mãe-criança: o mamar e o andar, o modo de dormir e o modo de morar. Sáo Paulo. Dissertação (Mestrado) - Instituto de Psicologia, Universidade de São Paulo.

Rabinovich, E.P. (1992). A casa dos sem casa. Psicologia, Ciência e Profissão, 12, $n^{\circ} .3 / 4,16-25$.

Rabinovich, E.P. (1993). La demeure des sans logis. Cahiers Santé, $3, n \div 5,375-81$.

Rabinovich, E.P. (1997). Vitrinespelhos transicionais da identidade um estudo de moradias e do ornamental em espaços sociais liminares brasileiros. São Paulo. Tese (Doutorado) - Instituto de Psicologia, Universidade de São Paulo.

Ribeiro, D. (1995). O povo brasileiro. São Paulo: Companhia das Letras.

Saile, D.G. (1985). The ritual establishment of home. Em Altman, I. e Werner, C.M. Home environments. New York: Plenum Press. v.8. Human behavior and environment.

Santos, B.S. (1995). Pelas mãos de Alice: o social e o político na pós-modernidade. São Paulo: Cortez.

Serres, M. (1993). Filosofia mestiça: le tiers-instruit. Rio de Janeiro: Nova Fronteira.

Tassara, E.T.O. (1996). Globalização, paradigmas e utopias: questōes de método na pesquisa social contemporânea. Em Camino et al., orgs. A sociedade na perspectiva da psicologia: questōes teóricas e metodológicas. Rio de Janeiro: ANPEPP.

Turner, V. (1974). O processo ritual: estrutura e anti-estrutura Petrópolis: Vozes.

Werner, C.M., Altman, 1. e Oxley, D. (1985). Temporal aspects of homes: a transactional perspective. Em Altman, I. e Werner, C.M. Home environments. New York: Plenum Press.

Zonabend, F. (1980). La mémoire longue: temps et histoires au village. Paris: PUF

\section{Referências bibliográficas}

